DOI: $10.17805 /$ zpu.2015.4.33

\title{
Первые выставки среднеазиатских работ В.В. Верещагина в периодической печати и проблема интерпретации произведений Туркестанского цикла
}

\author{
Е. Е. КРЫЛОВА \\ (САНКТ-ПЕТЕРБУРГСКИЙ ГОСУДАРСТВЕННЫЙ АКАДЕМИЧЕСКИЙ ИНСТИТУТ ЖИВОПИСИ, \\ СКУЛЬПТУРЫ И АРХИТЕКТУРЫ ИМ. И. Е. РЕПИНА)
}

Мнение историков искусства относительно картин из среднеазиатской серии (Туркестанский цикл) русского живописца и литератора В. В. Верещагина (1842-1904) сильно разнятся. Так, в советском искусствознании за Верещагиным закрепилась репутация прогрессивного художника-антимилитариста. В последние годы стало модно рассматривать Туркестанский цикл в рамках ориенталистского дискурса, где Верещагин предстает в образе художника, находившегося в авангарде имперской пропаганды. Видится целесообразным выяснить, как же современники Верещагина отозвались на первые выставки работ туркестанской серии. Это поможет взглянуть на творчество живописца с разных точек зрения и понять историческую обоснованность каждой из них.

Проанализировав отзывы прессы на две первые российские выставки Туркестанского цикла, можно заключить, что самые яростные критики художника сотрудничали с изданиями правоконсервативного толка («Русский мир», «Московские ведомости», «Современные известия»). Это факт, заставляющий усомниться в том, что данные работы Верещагина были восприняты как часть государственного (кауфмановского) проекта представления Туркестана и истории его завоевания.

Отчасти можно согласиться и с приверженцами трактовки Туркестанского цикла в рамках постколониального дискурса. То, что Верещагин впервые посетил Среднюю Азию в качестве художника, состоявшего при генерал-губернаторе края, его участие в Туркестанской выставке 1869 г. и характер большинства работ, представленных на ней, может свидетельствовать о том, что изначально действительно планировалось сделать произведения Верещагина частью государственного проекта репрезентации среднеазиатских владений империи.

Анализ публикаций, сопровождавших первые выставки туркестанских работ Верещагина, не только вводит в научный оборот неизвестные или малоизвестные публикации художественных критиков второй половины XIX в., но и позволяет лучше понять исторический контекст, в котором был создан Туркестанский цикл, наметить его взаимосвязи с течениями политической и общественной мысли России того периода.

Ключевые слова: В. В. Верещагин; Туркестанский цикл; русское искусство; ориентализм; постколониализм; художественная критика; Средняя Азия; империя; Россия

\section{BВЕАЕНИЕ}

ктуальность исследования обусловлена тем, что вопросы восточных влияний - и трактовки восточных сюжетов в творчестве русского живописца и литератора В. В. Верещагина (1842-1904) (как и в целом в русской живописи XIX в.) недостаточно изучены. В исследованиях, посвященных творчеству художника, во главу угла ставится антивоенное, гуманистическое начало творчества художника. Проблеме же конструирования образа Востока в произведениях Верещагина внимания практически не уделяется. За последние годы появились несколько работ, посвященных данному феномену. Вступая в резкую конфронтацию, с, казалось бы, устоявшимся взглядом на творчество художника, они трактуют произведения мастера в рамках постколониального дискурса, нередко нивелируя гуманистические идеи творчества художника. В результате подобного столкновения мнений произведения сложного, противоречивого мастера не получают комплексного анализа. Привлечение критических обзо- 
ров современников художника, недостаточно изученных современным научным знанием, может стать одним из инструментов, способным помочь выйти за рамки двух основных вариантов интерпретации творчества художника.

\section{ВЕРЕЩАГИН МЕЖАУ ИМПЕРИААИЗМОМ И АНТИМИАИТАРИЗМОМ}

В. Верещагин дважды совершал путешествия в Туркестан - в 1867 и 1869 гг. Первое - в качестве художника, состоявшего при Туркестанском генерал-губернаторе К. П. Кауфмане. Привезенные из этих путешествий эскизы и наброски легли в основу знаменитого Туркестанского цикла. Созданный в период с 1867 по 1873 г., он стал самым крупным и идеологически цельным проектом в истории русской ориентальной живописи XIX в. и одновременно одним из самых коммерчески успешных художественных проектов своего времени не только в русском, но и в западном искусстве в целом.

Мнения арт-критиков и историков искусства относительно картин из среднеазиатской серии достаточно сильно разнятся. Так, ведущие критики рубежа XIX-XX вв. А. Эфрос и А. Бенуа были настроены скептически в отношении художественной ценности работ Верещагина, видя в нем скорее ученого, нежели живописца. Затем в советском искусствознании за Верещагиным закрепилась репутация прогрессивного художника-антимилитариста. Ведущий специалист того периода по творчеству Верещагина А. К. Аебедев писал про работы туркестанского цикла: «...художник не может пройти мимо окружающих его сцен деспотизма, проявлений дикости, невежества, являющихся следствием отсталости и архаизма среднеазиатского общественного строя» (Иебедев, 1968: 18), а его батальные сцены «отличает их неподкупный реализм, суровая правда. Его полотна дают неприкрашенную, лишенную лакировки картину войны» (там же: 21). В своей интерпретации советские искусствоведы следовали за Ф. И. Булгаковым - автором первой монографии о творчестве художника (Булгаков, 1896) лично знакомым с мастером и состоявшим в дружеских отношениях с художником В. В. Стасовым, остающимся самым известным и влиятельным (если исходить из частоты цитирования) художественным критиком второй половины XIX в.

В последние годы стало модно рассматривать творчество Верещагина (и в первую очередь Туркестанский цикл) в рамках ориенталистского дискурса, восходящего к книге Э. Саида «Ориентализм», определившего, опираясь на труды М. Фуко, понятие «ориентализм» как «западный стиль доминирования, реструктурирования и осуществления власти над Востоком» (Саид, 2006: 10), т. е. как способ его колонизации. Авторы искусствоведческих исследований также традиционно обращаются к известной статье «Воображаемый Восток» $\Lambda$. Нохлин (Nochlin, 1983), использовавшей теорию Саида для выделения основополагающих стилевых отличий ориентальной живописи с точки зрения постколониального дискурса. Подобную интерпретацию творчества Верещагина можно встретить, например, в трудах Н. Медведев «Противопоставления в Туркестанском цикле Верещагина: визуализация Российской империи и ее “Аругих” ( (Medvedev, 2009), «Аругая история русского искусства» А. А. Бобрикова, где Туркестанский цикл описывается как «политический проект; искусство генерала Кауфмана» (Бобриков, 2012: 367), а «так называемый “пацифизм” Верещагина не есть обличение ужасов войны как таковых; это обличение ужасов войны именно средневековой, азиатской, “варварской” войны», где «демонстрация дикости <...> ставит вопрос о необходимости завоевания Туркестана цивилизованными народами» (там же: 368). 
Глядя на подобные столкновения противоположных по своей природе трактовок образа Верещагина и его творчества - образа художника - гуманиста и антимилитариста и образа художника, находившегося в авангарде имперской пропаганды, видится целесообразным выяснить ответ на следующий вопрос. Как же современники Верещагина отозвались на первые выставки работ туркестанской серии? Это может помочь взглянуть на творчество живописца с иных позиций, находящихся вне традиционных концепций трактовки его произведений, и одновременно помочь понять историческую обоснованность каждой из них.

$\mathrm{K}$ сожалению, в большинстве случаев при описании реакции современников художника на Туркестанский цикл исследователи ограничивались цитатами из статей B. В. Стасова (Стасов, 1894аb). Единственная на сегодняшний день работа, где сделана попытка более подробно рассмотреть данный вопрос, принадлежит американской исследовательнице Н. Медведев, которая отдельно останавливается на отклике английской прессы на лондонскую 1873 г. и российской прессы на петербургскую 1874 г. выставки (Medvedev, 2009).

\section{ТУРКЕСТАНСКАЯ ВЫСТАВКА 1869 ГОАА}

Рассмотрение реакции российской художественной критики на работы Верещагина, посвященные Средней Азии, начать следует с публикаций, сопровождавших Туркестанскую выставку 1869 г. (на которой художник впервые привлек внимание публики и критиков) и Петербургской выставки 1874 г. Московская же выставка, открывшаяся осенью того же года, проходила на фоне скандала, спровоцированного отказом Верещагина от звания академика и последовавшего за ним обвинения академика Н. $\Lambda$. Тютрюмова в том, что картины Верещагина писаны «компанейским способом» (Тютрюмов, 1874: 3). Это привело к тому, что обзоры выставки были практически вытеснены пикировкой между противниками и сторонниками живописца.

Первые свои работы (знаменитая серия «Варвары» на тот момент еще не была написана), созданные на сюжеты из жизни Средней Азии, Верещагин продемонстрировал на Туркестанской выставке 1869 г., носившей научно-популярный характер. Картины и рисунки художника там демонстрировались бок о бок с коллекциями оружия и костюмов жителей Средней Азии, а также с минералогической и зоологической коллекциями. В целом выставку характеризовали как «прекрасный случай ознакомиться наглядно с характером и физиономией страны, сделавшейся недавно русской провинцией» (Внутренние новости ... , 1869: 1). Среди представленных работ Верещагина критики единодушно выделили «После удачи», «После неудачи» и «Опиумоедов». Столь же единодушны они были в том, что работы художника «дают очень живое понятие о наружности и нравах жителей Туркестанского края» (там же). B «Санкт-Петербургских ведомостях» также отметили, что «туркестанские произведения г. Верещагина отличаются большими техническими достоинствами» (Кистин, 1869: 2). Но в целом сенсации работы художника тогда не произвели.

\section{ПЕТЕРБУРГСКАЯ ВЫСТАВКА 1874 ГОАА}

Впервые Туркестанский цикл в том виде, в котором он известен сегодня, был показан в России на экспозиции, открывшейся в Петербурге 7 марта 1874 г.

Вновь, как и в отзывах на выставку 1869 г., звучало, что работы художника «обогатят и, так сказать, иллюминуют его (зрителя. $-E$. K.) этнографические сведения о наших отдаленнейших окраинах》 (X. Z. X., 1874: 1), что живописец «так верно и глу- 
боко изучил типичные черты этой далекой и неведомой нам окраины <... так художественно воспроизвел их в своих произведениях, что приобрел себе право на самое серьезное внимание» $(\Lambda$-ичъ, 1874: 481). Из чего некоторые авторы выводили, что именно это придает особое историческое значение работам Верещагина, ведь «СреАняя Азия переживает в настоящую минуту кризис, долженствующий вскоре изменить не только нравы ее жителей, но и наружный вид местностей, где господствовал до сих пор склад жизни, не имеющий ничего общего с европейскими нравами и обычаями» (Внутренние новости ..., 1874: 2).

Идея о дикости нравов и обычаев Туркестанского края, «где на каждом шагу обступают вас - и незнакомая дикая природа, и незнакомые дикие люди» (А., 1874: 3), стала одним из лейтмотивов статей, посвященных выставке, повторенным на разные голоса всеми рецензентами. Это соответствовало замыслу художника, писавшего В. В. Стасову: «...сравнительно мало занялся собственно костюмом, хотя в такой стране, как Средняя Азия, он представляет для живописца благодатную почву: но это потому, что главное внимание было обращено на более серьезную задачу - охарактеризование того варварства, которым до сих пор пропитан весь строй жизни и порядков Средней Азии» (Верещагин, 1981: 30).

Споры возникли вокруг полотен, входящих в серию (сам художник называл ее «героической поэмой») «Варвары», и картины «Забытый» (позднее уничтоженной Верещагиным вместе с двумя картинами поэмы «У крепостной стены. Вошли!» и «Окружили - преследуют...»), посвященных военному противостоянию русских войск и туземного населения Туркестанского края.

Автор «Русского мира» увидел в них изображение «боевой жизни и обстановки нашего русского солдата, заброшенного судьбой в этот неприветливый край <..> эпопеи <...> тяжких трудов, лишений и доблестных подвигов» (X. Z. X., 1874: 1). Схожую точку зрения высказал и журналист «Биржевых ведомостей»: «...гядя на картины г. Верещагина, а именно на сцены борьбы русских героев, малых числом, со скопищами врагов, оставшихся верными своей разбойничьей тактике, - невольно, сама собою, проводится параллель этой борьбы с законченною драмою покорения Кавказа. И там ожесточение изуверов-противников пало перед стойкостью и геройством русского солдата» (П-в, 1874: 2). Им вторят авторы «Недели»: «...это - поэма среднеазиатской войны, в которой, между прочим, так резко обрисовался тип русского солдата, закинутого на далекий восток, где ему пришлось в одно и то же время быть и завоевателем, и защитником, и первым колонизатором» $(\Lambda$-ичъ, 1874: 482) и «Туркестанских ведомостей»: «...вы не можете оторваться от всех әтих говорящих, стонущих подробностей, вы не можете уйти, безучастно взглянув на этих живых людей, этих героев, и не подозревающих даже, что к ним может относиться такое название - так они просты, не мудры, человечны в своем предсмертном героизме» (Иьвович, 1874: 83).

Аругие критики трактовали их как произведения, по своему духу антивоенные. В. В. Стасов в «Санкт-Петербургских ведомостях» писал: «...у нашего художника всего громче звучит нота негодования и протеста против варварства, бессердечия и холодного зверства, где бы и кем бы эти качества ни пускались в ход» (Стасов, 1894а: 502). Еще резче высказался анонимный критик в газете «Голос»: «...разит всякое восхваление войны» (Урок русским художникам ..., 1874: 1), однако в завершении статьи писавший: «...это изображение целой громадной страны, которую мы завоевали и которую цивилизуем» (там же: 2). 
Критик же из «Московских ведомостей» (издания, имевшего реакционную правоконсервативную репутацию) увидел в этих картинах восхваление «средне-азиатских разбойников»: «...встретясь со словом “героический”, вы, конечно, предполагаете, что эпитет этот относится к подвигам русских войск... ничуть не бывало. Герои - это Туркмены, побеждающие Русских и торжествующие свою победу. Поэт-художник воспевает их подвиги и венчает их апофеозой из пирамиды человеческих черепов» (А., 1874: 3). Хотя также относимые к газетам правым и реакционным «Русский мир» и «Туркестанские ведомости», печатавшиеся при канцелярии Туркестанского генерал-губернатора, как видно из выше приведенных цитат, на тот момент дали положительные отзывы о выставке. Правда, несколько месяцев спустя именно «Русский мир» станет главной трибуной для академика Н. $\Lambda$. Тютрюмова, обвинившего Верещагина в том, что он дишь автор первоначальных эскизов, в сами картины писаны некой артелью художников в Мюнхене, а заодно и в применении низкопробных коммерческих ходов для привлечения публики. Возвращаясь же к отзыву на выставку, помещенному в «Московских ведомостях», стоит отметить, что вызвавшая резкую критику генералгубернатора Туркестана картина «Забытый» была оценена выше большинства картин, представленных на выставке: «...из картин, в которых чувствуется настоящее вдохновение, мы могли бы указать только одну: Забытый» (там же: 3).

Проанализировав отзывы прессы на две первые российские выставки Туркестанского цикла, можно заключить, что самые яростные критики художника сотрудничали с изданиями правоконсервативного толка ( Русский мир», «Московские ведомости», «Современные известия»). Это факт, заставляющий усомниться в том, что данные работы Верещагина были восприняты как часть государственного (кауфмановского) проекта представления Туркестана и истории его завоевания. Более того, уже в текстах первых отзывов на картины среднеазиатской серии звучат антивоенные мотивы, ставшие основными в работах советских историков искусства, что в известной мере легитимирует эту интерпретацию Туркестанского цикла. Однако, говоря об антимилитаристской направленности произведений цикла, следует учитывать, что антивоенные убеждения как Верещагина, так и его рецензентов существовали в рамках позитивистской модели видения мира, не только не исключавшей, но даже пропагандировавшей цивилизаторскую миссию более развитых цивилизаций.

Отчасти можно согласиться и с приверженцами трактовки Туркестанского цикла в рамках постколониального дискурса. То, что Верещагин впервые посетил Среднюю Азию в качестве художника, состоявшего при генерал-губернаторе края, его участие в Туркестанской выставке 1869 г. и характер большинства работ, представленных на ней, может свидетельствовать о том, что изначально действительно планировалось сделать произведения Верещагина частью государственного проекта репрезентации среднеазиатских владений империи. К моменту знакомства с К. П. Кауфманом Верещагин был известен дишь своими рисунками Кавказа этнографического характера (будущий стиль художника, произведший не одну сенсацию, по ним фактически невозможно предположить) - изображения подобного рода были бы совершено уместны в рамках официального проекта визуализации новых колоний.

\section{ЗАКАЮЧЕНИЕ}

Исследование показывает, что анализ публикаций, сопровождавших первые выставки туркестанских работ Верещагина, не только вводит в научный оборот неизвестные или малоизвестные публикации художественных критиков второй половины 
XIX в. и позволяет лучше понять исторический контекст, в котором был создан Туркестанский цикл, и наметить его взаимосвязи с течениями политической и общественной мысли России того периода, но и выявляет, что столь четкой, как сегодня, границы между империалистической и антимилитаристской позициями в общественной мысли второй половины XIX в. еще не существовало.

\section{СПИСОК АИТЕРАТУРЫ}

А. (1874) Новая художественная выставка в Петербурге // Московские ведомости. №64. С. 3. Булгаков, Ф. И. (1896) Василий Васильевич Верещагин и его произведения. СПб. : Тип. А. С. Суворина. 95 с.

Бобриков, А. А. (2012) Аругая история русского искусства. М. : Новое литературное обозрение. 744 с.

Верещагин, В. В. (1981) Избранные письма / сост., авт. предисл. и примеч. А. К. Аебедев. М. : Изобразительное искусство. 287, [11] с.

Внутренние новости. Петербургская хроника (1869) // Голос. № 86. С. 1.

Внутренние новости. Петербургская хроника (1874) // Голос. № 66. С. 2.

Кистин [Сомов, А. И.] (1869) Заметки о художествах // Санкт-Петербургские ведомости. № 105 . C. 2.

Иебедев, А. К. (1968) В. В. Верещагин. М. : Искусство. 63 с.

$\Lambda$-ичъ. (1874) Поэма в красках // Неделя. № 13. С. 481-483.

$\Lambda$ ьвович, А. (1874) Выставка картин художника Верещагина в С.-Петербурге // Туркестанские ведомости. №21. С. 83.

П-в [Петров, П. Н.] (1874) Работы Верещагина и конкурсы на премии «Общества поощрения художников» // Биржевые новости. № 85. С. 1-2.

СаиА, Э. В. (2006) Ориентализм. Западные концепции Востока / пер. с англ. А. В. Говорунова. СПб. : Русский міръ. 636 с.

Стасов, В. В. (1894) Собр. соч. 1847-1886 : в 4 т. СПб. : Тип. М. М. Стасюлевича. Т. 1. [1680] стб.

Стасов, В. В. (1894) Собр. соч. 1847-1886 : в 4 т. СПб. : Тип. М. М. Стасюлевича. Т. 2. XVI, [1050] стб., [6] с.

Тютрюмов, Н. А. (1874) Несколько слов касательно отречения г. Верещагина от звания профессора живописи // Русский мир. № 265. С. 3.

Урок русским художникам (Выставка В. В. Верещагина) (1874) // Голос. № 82. С. 1-2.

X. Z. X. (1874) Явления современной жизни. Выставка картин г. Верещагина (Туркестан) // Русский мир. № 66. С. 1.

Nochlin, L. (1983) The imaginary orient // Art in America. Vol. 71. No. 5. P. 118-131; 187-191.

Medvedev, N. (2009) The contradictions in Vereshchagin's Turkestan series: Visualizing the Russian empire and its others : A diss. Los Angeles : University of California. 303 leaves.

Aата поступления: 15.09 .2015 2.

\section{FIRST EXHIBITIONS OF V. V. VERESHCHAGIN'S WORKS FROM CENTRAL ASIA IN PRESS AND THE PROBLEM OF THE TURKESTAN SERIES INTERPRETATION \\ E. E. KRYLOVA \\ (Ilya Repin St. Petersburg State Academic Institute of Fine Arts, Sculpture and Architecture)}

Vasily Vereshchagin visited Turkestan twice - in 1867 and then in 1869. His first visit to Turkestan was on special commission from the Governor General of Russian Turkestan Konstantin Kaufman. Vereshchagin's well-known Turkestan series is based on images created during these trips.

There is no single opinion about how to interpret this cycle among art historians. On the one hand, in Soviet times Vereshchagin's reputation was that of a progressive artist and a pacifist. On the other, contemporary scholars prefer to locate the Turkestan series within the Orientalist discourse, and the 
artist himself, in the vanguard of imperialist propaganda. In order to re-examine the works of the painter from multiple perspectives, it is thus important to understand how Vereshchagin's contemporaries responded to the first exhibitions of his Turkestan series.

Our analysis of media responses to the first two of such exhibitions has shown that Vereshchagin's main opponents published their articles in right-wing papers (The "Russkiy Mir", "Moskovskie Vedomosti", "Sovremennye Izvestiia"). It is thus highly doubtful that the Turkestan cycle was perceived as part of the official colonial project.

Nevertheless, the postcolonial interpretation of the cycle does have a reason. Vereshchagin's commission from the Governor General, his participation in the Turkestan Exhibition of 1869, as well as the paintings he exhibited there - all of these factors leave some ground for speculating that his works could have been planned to form a part of Kaufman's project for Central Asia as part of the empire.

We can conclude that the analysis of the publications discussing Vereshchagin's first exhibitions of the Turkestan series both puts little-known works of art criticism in the limelight and helps us understand the historical context of the series and locate it within Russia's political and social thought of the time.

Keywords: Vasily Vereshchagin; Turkestan series; Russian art; Orientalism; postcolonialism; art criticism; Central Asia; empire; Russia

\section{REFERENCES}

A. (1874) Novaia khudozhestvennaia vystavka v Peterburge [A new art exhibition in Petersburg]. Moskovskie vedomosti, no. 64, p. 3. (In Russ.).

Bulgakov, F. I. (1896) Vasilii Vasil'evich Vereshchagin i ego proizvedeniia [Vasily Vasilyevich Vereshchagin and his works]. St. Petersburg, Tipografiia A. S. Suvorina [A. S. Suvorin's Printing House]. 95 p. (In Russ.).

Bobrikov, A. A. (2012) Drugaia istoriia russkogo iskusstva [Another history of Russian art]. Moscow, Novoe literaturnoe obozrenie Publ. 744 p. (In Russ.).

Vereshchagin, V. V. (1981) Izbrannye pis' ma [Selected letters]/ comp., introduction and notes by A. K. Lebedev. Moscow, Izobrazitel'noe iskusstvo Publ. 287, [11] p. (In Russ.).

Vnutrennie novosti. Peterburgskaia khronika [Local news. Petersburg chronicle]. (1869) Golos, no. 86, p. 1. (In Russ.).

Vnutrennie novosti. Peterburgskaia khronika [Local news. Petersburg chronicle]. (1874) Golos, no. 66, p. 2. (In Russ.).

Kistin [Somov, A. I.]. (1869) Zametki o khudozhestvakh [Notes on fine arts]. Sankt-Peterburgskie vedomosti, no. 105 , p. 2. (In Russ.).

Lebedev, A. K. (1968) V. V. Vereshchagin [V. V. Vereshchagin]. Moscow, Iskusstvo Publ. 63 p. (In Russ.).

L-ich (1874) Poema v kraskakh [A poem in colours]. Nedelia, no. 13, pp. 481-483. (In Russ.).

Lvovich, D. (1874) Vystavka kartin khudozhnika Vereshchagina v S.-Peterburge [An exhibition of Vereshchagin's paintings in St. Petersburg]. Turkestanskie vedomosti, no. 21, p. 83. (In Russ.).

P-v [Petrov, P. N.]. (1874) Raboty Vereshchagina i konkursy na premii «Obshchestva pooshchreniia khudozhnikov» [Vereshchagin's works and the Society for the Encouragement of the Arts award]. Birzhevye novosti, no. 85, pp. 1-2. (In Russ.).

Said, E. W. (2006) Orientalizm. Zapadnye kontseptsii Vostoka [Orientalism: Western conceptions of the Orient] / transl. from English A. V. Govorunov. St. Petersburg, Russkii mir» Publ. 636 p. (In Russ.).

Stasov, V. V. (1894a) Sobranie sochinenii. 1847-1886 [Collected works, 1847-1886] : in 4 vols. St. Petersburg, Tipografiia M. M. Stasiulevicha [M. M. Stasiulevich's Printing House]. Vol. 1. [1680] clmns. (In Russ.).

Stasov, V. V. (1894b) Sobranie socbinenii. 1847-1886 [Collected works, 1847-1886] : in 4 vols. St. Petersburg, Tipografiia M. M. Stasiulevicha [M. M. Stasiulevich's Printing House]. Vol. 2. XVI, [1050] clmns., [6] p. (In Russ.). 
Tiutriumov N. L. (1874) Neskol'ko slov kasatel'no otrecheniia g. Vereshchagina ot zvaniia professora zhivopisi [Several words on Vereshchagin's resignation as professor of painting]. Russkii mir, no. 265, p. 3. (In Russ.).

Urok russkim khudozhnikam (Vystavka V.V. Vereshchagina) [A lesson for Russian artists. (V. V. Vereshchagin's exhibition)]. (1874) Golos, no. 82, pp. 1-2. (In Russ.).

X.Z. X. (1874) Iavleniia sovremennoi zhizni. Vystavka kartin g. Vereshchagina (Turkestan) [Scenes of modern life. An exhibition of Vereshchagin's paintings (Turkestan)]. Russkii mir, no. 66, p. 1. (In Russ.).

Nochlin, L. (1983) The imaginary orient. Art in America, vol. 71, no. 5, pp. 118-131; 187-191.

Medvedev, N. (2009) The contradictions in Vereshchagin's Turkestan series: Visualizing the Russian empire and its others: A diss. Los Angeles, University of California. 303 leaves.

Submission date: 15.09.2015.

Крылова Елизавета Евгеньевна - соискатель степени кандидата наук кафедры русского искусства Санкт-Петербургского государственного академического института живописи, скульптуры и архитектуры им. И. Е. Репина. Адрес: 198330, Россия, г. Санкт-Петербург, Университетская набережная, д. 17. Тел.: +7 (812) 323-67-77. Эл. адрес: eekrylova@gmail.com. Научный руководитель - А-р искусств., проф. Е. В. Нестерова.

Krylova Elizaveta Evgenievna, External postgraduate student, Department of Russian Art, Ilya Repin St. Petersburg State Academic Institute of Fine Arts, Sculpture and Architecture. Postal address: 17 Universitetskaya naberezhnaya, 198330 St. Petersburg, Russian Federation. Tel.: +7 (812)323-67-77. E-mail: eekrylova@gmail.com. Research adviser: Doctor of Art Studies, Professor E. V. Nesterova. 